\title{
Preliminary results of long-term slip rates of 1999 earthquake fault by luminescence and radiocarbon dating
}

\author{
Yue-Gau Chen ${ }^{\mathrm{a}, *}$, Ya-Wen Chen ${ }^{\mathrm{a}}$, Wen-Shan Chen ${ }^{\mathrm{a}}$, Jia-Fu Zhang ${ }^{\mathrm{b}}$, Hui Zhao, \\ Li-Ping Zhou ${ }^{\mathrm{b}}$, Sheng-Hua $\mathrm{Li}^{\mathrm{c}}$ \\ ${ }^{a}$ Department of Geosciences, National Taiwan University, No. 1, Sec. 4th, Roosevelt Rd., Taipei 106, Taiwan, ROC \\ ${ }^{\mathrm{b}}$ Department of Geography, Peking University, Beijing 100871, People's Republic of China \\ ${ }^{\mathrm{c}}$ Department of Earth Sciences, The University of Hong-Kong, Rm 309, James Lee Science Bldg, Pokfulam Rd., Hong Kong
}

\begin{abstract}
For the purpose of deriving the long-term slip rates of different segments along the surface rupture of 1999 Chi-chi earthquake, radiocarbon and luminescence methods (TL and OSL) were applied to the tectonically influenced geomorphic features and deposits. We obtained six age estimates on pottery, driftwood and fluvial sediments. We found that the OSL signals of the samples collected from the coarse fluvial deposits had not been totally bleached due to rapid deposition. Based on the cumulative vertical offsets, the vertical slip rates were computed for each site. Our results reveal that the slip rate of the northern segment is relatively higher than that of the southern segment, which is consistent with the coseismic offsets that occurred in the 1999 earthquake.
\end{abstract}

(C) 2003 Elsevier Science Ltd. All rights reserved.

\section{Introduction}

Taiwan is located in an active plate boundary, where an arc-continent collision event has been occurring for several million years since late Miocene (Ho, 1988; Teng, 1990; Fig. 1a). Based on the neotectonic and geomorphological studies, this collision event is still going on and the active structures are widely distributed in Taiwan (Bonila, 1975; Chang et al., 1998; Lin et al., 2001). In 1999, a large earthquake, Chi-chi, struck central Taiwan and the associated surface rupture ran through the urban area following the established Chelungpu fault (Fig. 1b; Ma et al., 1999; Rubin et al., 2001; Y.G. Chen et al., 2002a). It is one of the major boundary thrusts (see the cross-section in Fig. 1) in the western front of a fold-and-thrust belt that is created by the arc-continent collision mentioned above. The surface offsets and focal mechanism of the main shock are both consistent with the thrusting behavior (Fig. 1). The rupture extends about $100 \mathrm{~km}$ from north to south, with variations in the offsets. Post-earthquake investigations showed a trend of decreasing offsets southward (CGS, 1999; Y.G. Chen et al., 2001),

*Corresponding author. Tel.: +886-2-23697648; fax: +886-223636095.

E-mail address: ygchen@ccms.ntu.edu.tw (Y.-G. Chen). indicating that the fault is segmented (Fig. $1 \mathrm{~b}$ and c). As shown in Fig. 1c, the 1999 rupture can be divided into four segments (Y.G. Chen et al., 2001). To further clarify this question and to work on the assessment of earthquake hazards, we recognized that a paleoseismology study was urgently needed (McCalpin, 1996). The essential task in paleoseismology studies is to derive the slip rates of each segment. Segment I to the south is strike-slip dominant with less and various vertical displacements, resulting in inconsistent geomorphic features (Fig. $1 b$ and c). Instead of a unique surface trace with significantly cumulative strain, segment IV is composed of many secondary folds and faults, which are inappropriate targets for slip rate studies with respect to the main fault. We therefore only focus on segments II and III, the thrusting segments. Post-earthquake investigation of the two segments demonstrated a general trend of decreasing coseismic displacements from north to south (Fig. 1c; CGS, 1999). This project was aimed at making comparison between the 1999 coseismic slip and the long-term slip rates recorded in associated deposits and landforms. This comparison may allow us to understand the slip behavior of Chelungpu fault, whether it follows a model of variable slip or uniform slip (McCalpin, 1996) and whether the 1999 event was a characteristic earthquake (Berryman and Beanland, 1991). 


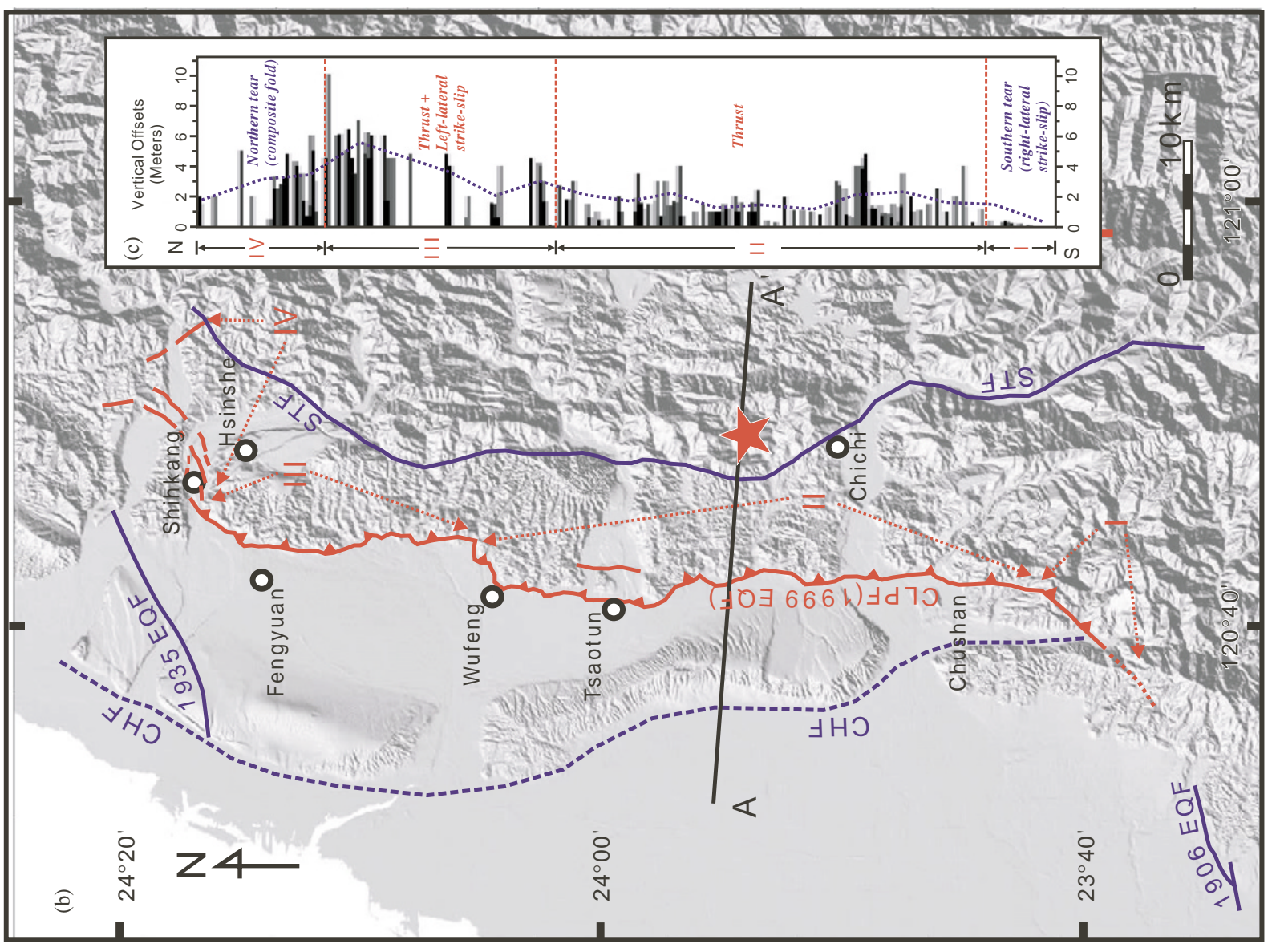

焉莺

蓉递

.

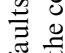

흐

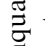

ซ๊

芩

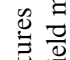

至

훙

吾

芯

牙

橧交

运玄

อิ

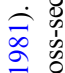

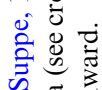

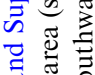

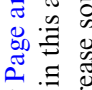

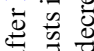
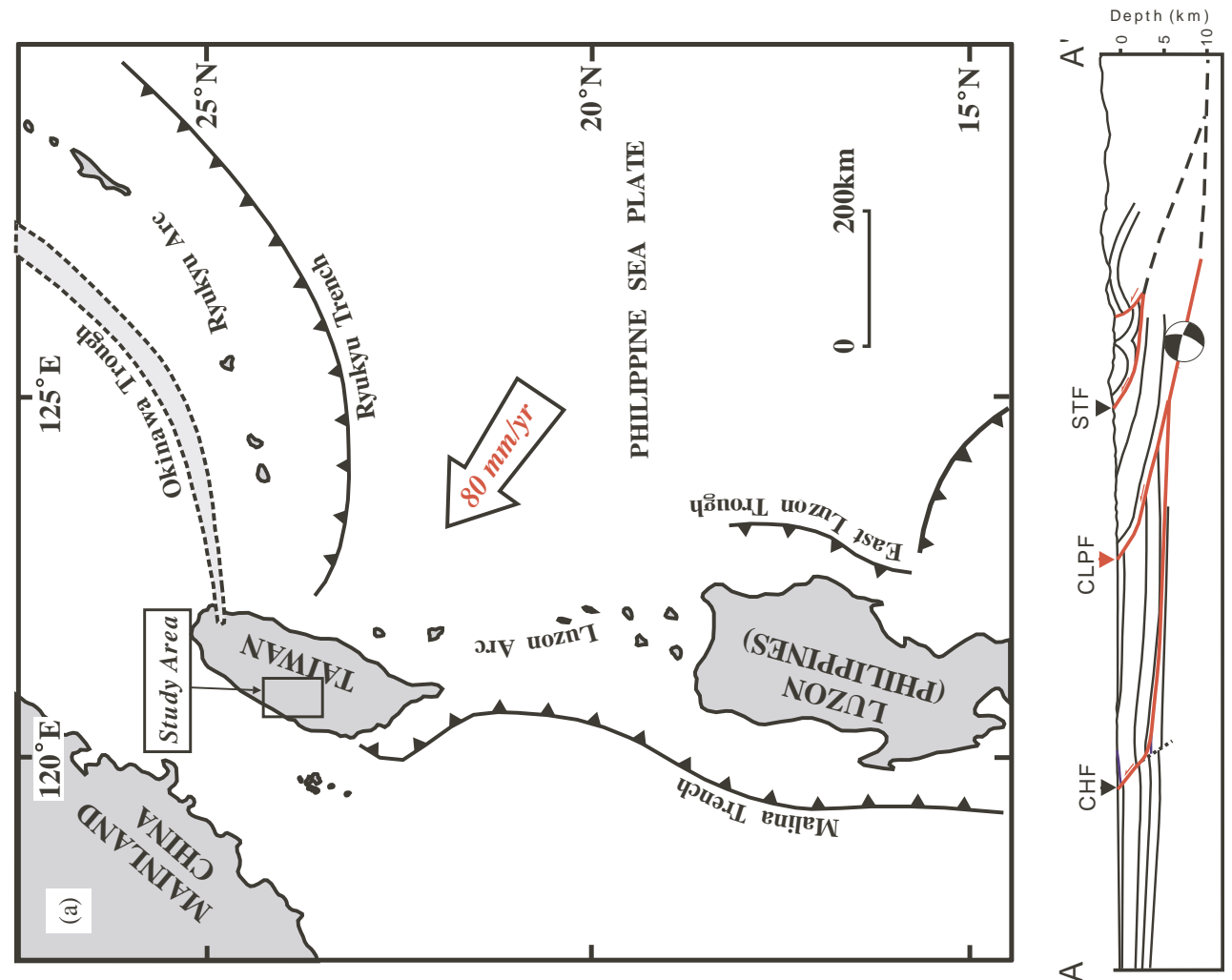

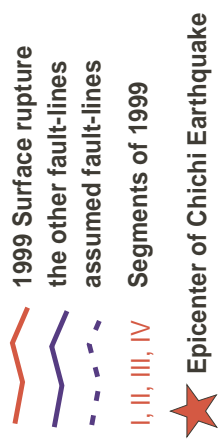

$\exists \frac{\square}{0}$

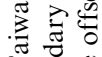

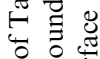

궁

焉

可

.

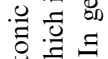

范

호

这

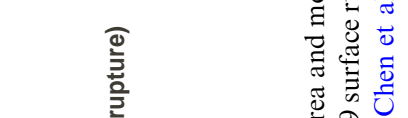

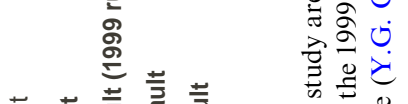

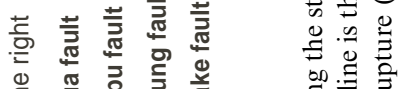

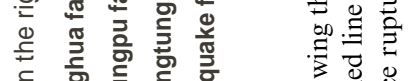

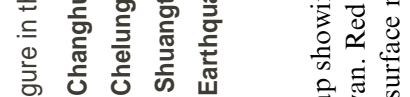

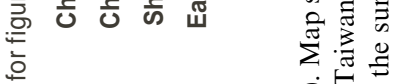

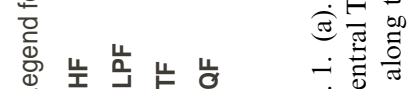

ab. 
To compute the slip rates, the ages of related geomorphic feature and sedimentary sequence have to be worked out by geochronological methods, such as luminescence and radiocarbon. It is difficult to find appropriate samples for radiocarbon dating in coarse fluvial deposits. Unfortunately, cobbles are the most common fluvial deposits in Taiwan. The TL method is available on pottery samples, which are occasionally found in culturally linked horizon. We further adopted optically stimulated luminescence to independently determine the age of fluvial sediments.

\section{Methodology and results}

In total, we collected two wood ( $\# 4$ and $\# 6$ ), two pottery ( $\# 1$ and $\# 3$ ) and two sediment samples ( $\# 2$ and \#5) within faulting related deposits at five sites (Fig. 1b) along the Chelungpu fault.

\subsection{Radiocarbon method}

The wood samples ( $\# 4$ and $\# 6$ ) were analyzed in the radiocarbon laboratory at National Taiwan University. The samples were both well-preserved and over $20 \mathrm{~g}$ in dry weight. We stripped the outer parts and conducted the routine cleaning method a few times to prevent possible contamination. The uncalibrated ages are $1670 \pm 40$ and $11590 \pm 60 \mathrm{BP}$. The tree-ring calibrated ages are $1420-1690$ and 13,320-13,850 Cal BP, respectively (Table 1).

\subsection{TL method}

We used the fine-grained additive dose method (Aitken, 1985) on pottery samples collected from the Shihkang terrace $(\# 1)$ and Wufeng trench $(\# 3)$ to derive the equivalent dose $\left(D_{\mathrm{e}}\right)$. Sample \#1 was collected within the layers, not from the capping soil. Also sample has angular shape, indicating its in situ origin. The age of the pottery sample is believed very close to the formation age of the terrace. Sample \#3 is also angular, but was collected from a layer within the entire sequence of fluvial deposits. The pottery age may represent the deposition age of the layer where it appears. The dating materials were taken from the inner portion, $1.5 \mathrm{~mm}$ away from the pottery surface, and were measured at least five times in a dark room. The glow curve, plateau test, selected temperature range, and $D_{\mathrm{e}}$ regression for one of the measurements are shown in Fig. 2. Glow curves show the highest peaks are both located within $300-400^{\circ} \mathrm{C}$, indicating quartz signal dominance: according to the peak positions, the temperature regains of $260-380^{\circ} \mathrm{C}$ and $300-400^{\circ} \mathrm{C}$ were integrated for samples $\# 1$ and $\# 3$, respectively. Second glow regressions show very small correction values for both of the $\# 1$ and $\# 3$, indicating that supra-linearity can be ignored. Linear regression was used as both samples did not show saturation effects. The dose rate was determined by ICPmass spectrometry and XRF for uranium (U), thorium (Th) and potassium (K). Alpha correction factors were 0.061 and 0.063 , respectively (Aitken, 1985). Water contents of surrounding sediments were assumed to be $20 \%$ since both samples were collected from layers of medium to coarse sand located near the ground water table. Beta and gamma attenuation were corrected for the thickness of the pottery samples (Aitken, 1985). The relevant data of pottery samples are presented in Table 2. The computed ages are 1880 and $830 \mathrm{yr}$ and the uncertainties are given as 90 and $80 \mathrm{yr}$, respectively, based on regression error.

\subsection{OSL method}

Two fluvial sandy samples were collected from the higher terraces at Hsinshe $(\# 2)$ and Tsaotun $(\# 5)$ for OSL dating. We adopted the quartz inclusion method. The grain size fraction of 90 to $180 \mu \mathrm{m}$ was extracted by sieving, then immersed in $\mathrm{HCl}(10 \%)$ and $\mathrm{H}_{2} \mathrm{O}_{2}(10 \%)$ for at least $1 \mathrm{~h}$ to remove the carbonate and organic matter. Thereafter, $10 \%$ and condensed HF was used to dissolve feldspar and to etch the alpha-affected surface of quartz. We finally screened out the grain size of 90 to $112 \mu \mathrm{m}$ for further measurements. IR-OSL was tested for checking the feldspar existence; otherwise, HFetching was repeated until the absence of IR-OSL indicated the complete removal of the feldspar components. For each sample we implemented preheat plateau, thermal transfer, dose recovery (Fig. $3 \mathrm{a}$ and b), and growth curve (Fig. 3c and d) to test the preheat temperature, thermal effect, recycling ability, and saturation, respectively. The OSL characteristics indicate that the sample from Tsaotun is better suited for dating than the Hsinshe sample. However, the growth curve of Hsinshe indicates that it could be suitable for OSL dating because the $D_{\mathrm{e}}$ value is lower than the

Table 1

Radiocarbon ages of samples collected from Wufeng trench and Chushan terrace

\begin{tabular}{llllccc}
\hline Sample no. & Locality & Longitude/latitude & Lab. no. & Conventional age (yr BP) & Calibrated age $^{\text {a }}($ Cal. BP) & Materials \\
\hline$\# 4$ & Wufeng & $120^{\circ} 42^{\prime} 10^{\prime \prime} / 24^{\circ} 04^{\prime} 34^{\prime \prime}$ & NTU-3575 & $1670 \pm 40$ & $1420-1690$ & Wood \\
$\# 6$ & Chushan & $120^{\circ} 43^{\prime} 10^{\prime \prime} / 24^{\circ} 45^{\prime} 30^{\prime \prime}$ & NTU-3739 & $11,590 \pm 60$ & $13,320-13,850$ & Wood \\
\hline
\end{tabular}

${ }^{\text {a }}$ Ages are calibrated following Stuiver and Reimer (1993). 


\section{\#1 Shihkang}

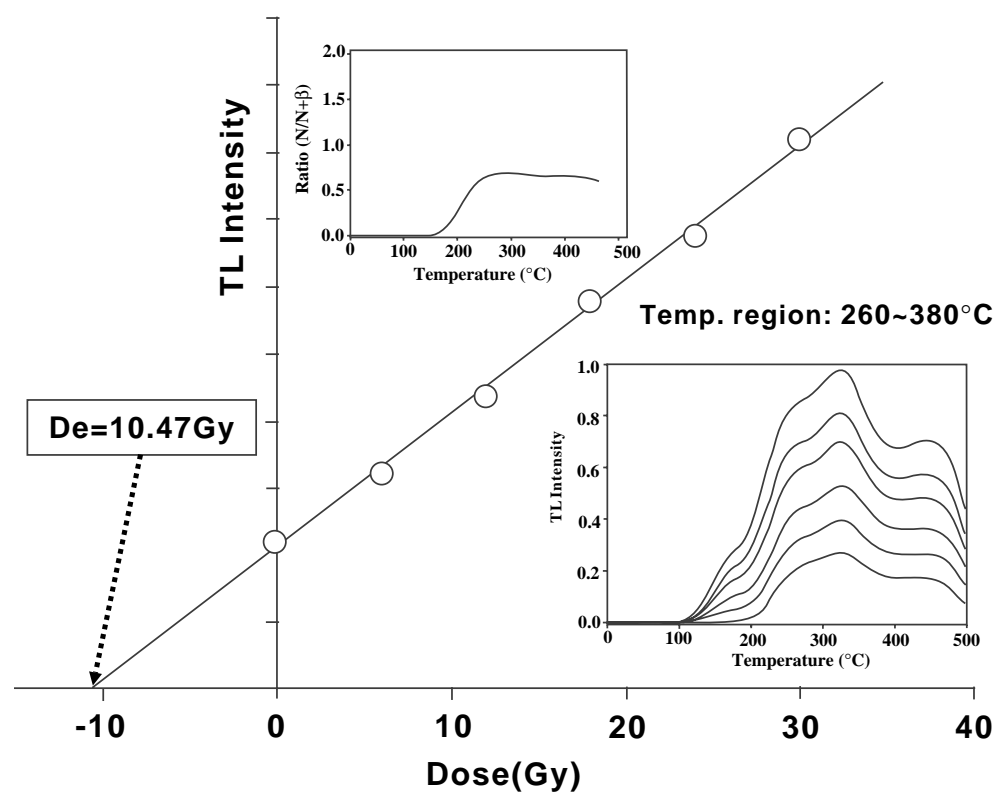

\section{\#3 Wufeng}

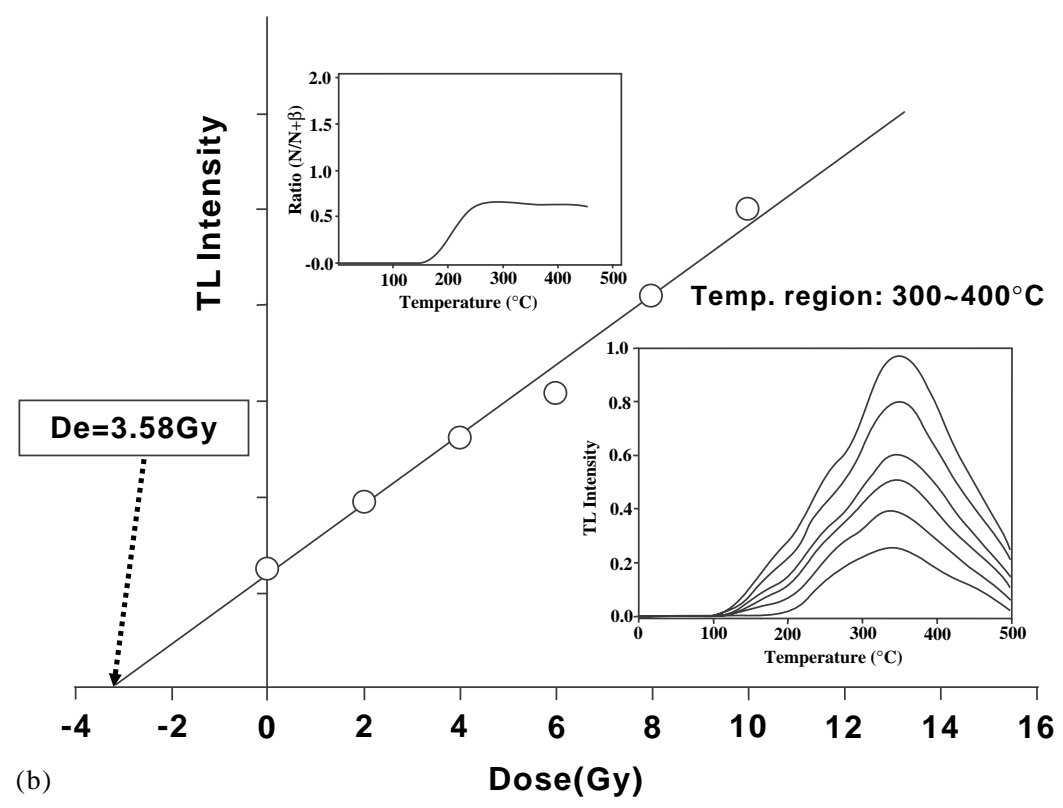

Fig. 2. TL measurements of pottery samples collected from terrace deposits at Shihkang and Wufeng.

saturation point of about 500-600 Gy (Fig. 3c). The single aliquot regenerative (SAR) protocol was used to derive $D_{\mathrm{e}}$ values (Murray and Roberts, 1998; Murray and Wintle, 2000). Over 20 aliquots for each sample were measured. Unfortunately, both of the OSL samples gave scattered $D_{\mathrm{e}}$ distribution (Fig. 3e and f), which is the result of incomplete bleaching during quick deposition (Li, 1994). Poorly bleached aliquots were rejected (Table 3) using the screening method of Li (2001), who showed that the intensity ratio of OSL over $110^{\circ} \mathrm{C}$ TL generated by a small test dose does not change for wellbleached samples, but is sensitive to poorly bleached samples. Dose rate determinations for OSL follow the same procedures as TL. Since the samples were both collected from sandy layers around water table, the water content was assumed to be $20 \%$. The final OSL ages for Hsinshe and Tsaotun terraces were 55.0 \pm 12.6 and $13.5 \pm 2.5 \mathrm{ka}$, respectively. 
Table 2

Parameters for dose rate derivation and luminescence age calculation

\begin{tabular}{|c|c|c|c|c|c|c|}
\hline Sample no. & Locality & $\mathrm{U}_{\mathrm{i}} / \mathrm{U}_{\mathrm{e}}^{\mathrm{a}}(\mathrm{ppm})$ & $\mathrm{Th}_{\mathrm{i}} / \mathrm{Th}_{\mathrm{e}}(\mathrm{ppm})$ & $\mathrm{K}_{\mathrm{i}} / \mathrm{K}_{\mathrm{e}}(\%)$ & $k$-value $/ p$-value & Water $_{\mathrm{i}} /$ Water $_{\mathrm{e}}(\%)$ \\
\hline$\# 1$ (TL) & Shihkang & $2.52 / 9.77$ & $12.22 / 19.93$ & $1.73 / 1.72$ & $0.061 / 10.95$ & $-/ 0.20$ \\
\hline$\# 2(\mathrm{OSL})$ & Hsinshe & 2.84 & 11.84 & 1.96 & - & 0.20 \\
\hline$\# 3$ (TL) & Wufeng & $2.34 / 3.44$ & $11.96 / 20.17$ & $1.56 / 1.08$ & $0.06 / 10.33$ & $-/ 0.20$ \\
\hline$\# 5$ (OSL) & Tsaotun & 3.14 & 17.44 & 2.04 & - & 0.20 \\
\hline$\alpha$ dose $(\mathrm{Gy} / \mathrm{kyr})$ & $\beta$ dose $(\mathrm{Gy} / \mathrm{kyr})$ & $\gamma$ dose $(\mathrm{Gy} / \mathrm{kyr})$ & Cosmic ray (Gy/kyr) & Annual dose (Gy/kyr) & Equivalent dose (Gy) & Age (yr) \\
\hline 0.98 & 2.48 & 1.95 & 0.15 & 5.56 & $10.47 \pm 0.47$ & $1880 \pm 90$ \\
\hline- & 1.50 & 1.09 & 0.15 & 2.75 & $151.0 \pm 34.6$ & $55,000 \pm 12,600$ \\
\hline 0.97 & 1.87 & 1.33 & 0.15 & 4.32 & $3.58 \pm 0.37$ & $830 \pm 80$ \\
\hline- & 1.70 & 1.36 & 0.15 & 3.21 & $43.3 \pm 8.0$ & $13,500 \pm 2500$ \\
\hline
\end{tabular}

a Subscripts 'i' and 'e' represent 'internal' and 'external' respectively.
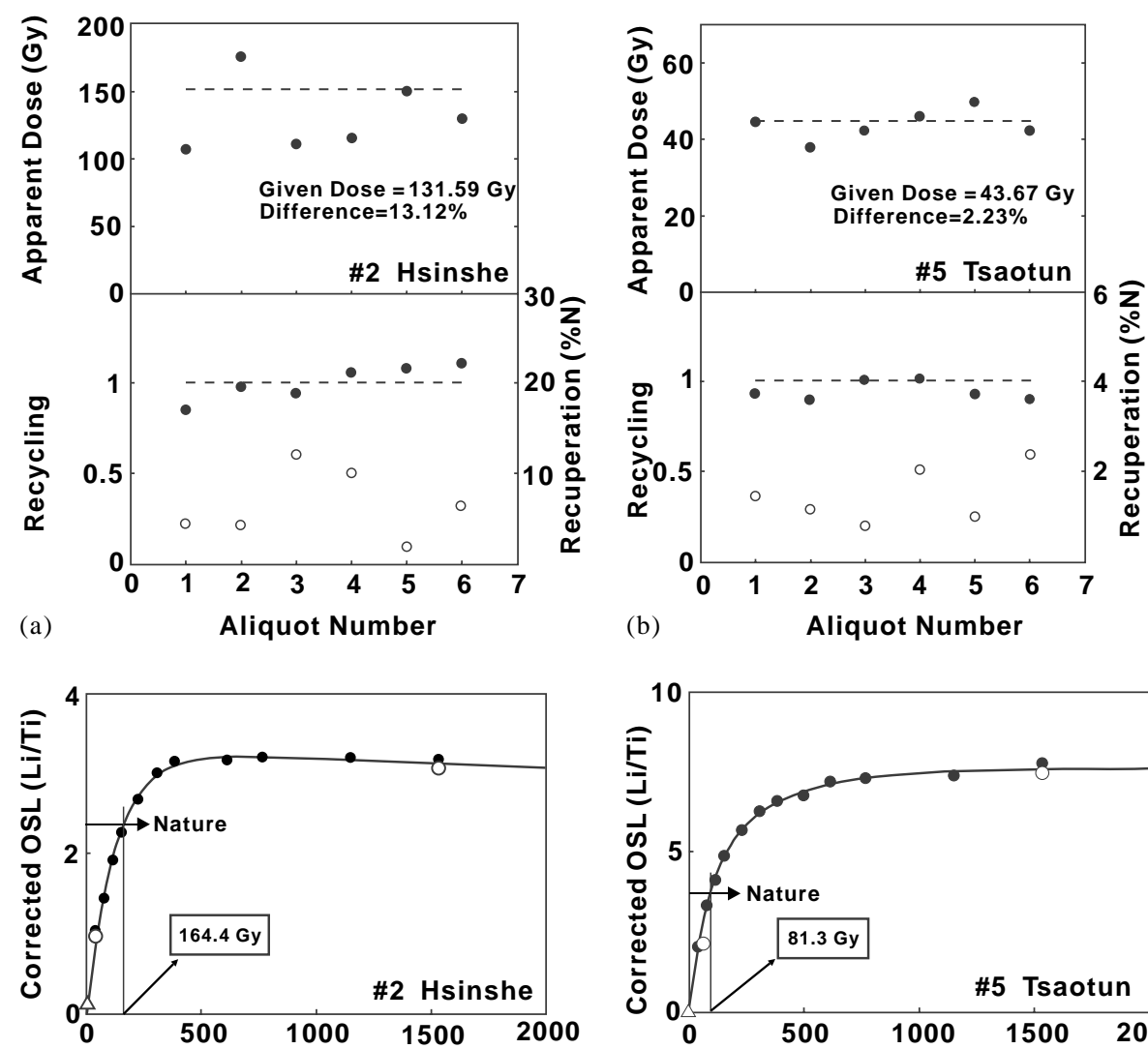

(b)

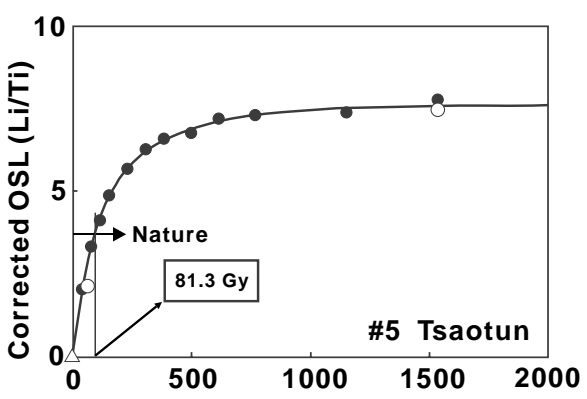

(c) Regeneration Dose (Gy)

(d) Regeneration Dose (Gy)

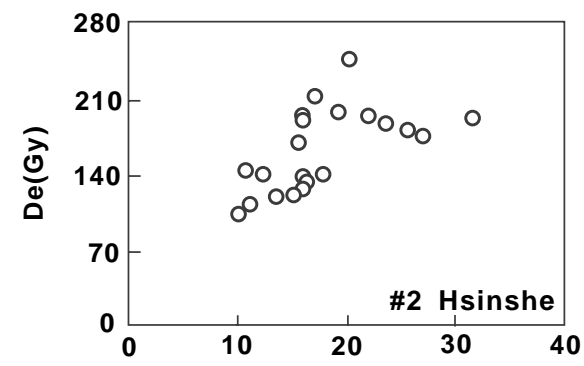

(e)

Corrected Natural OSL

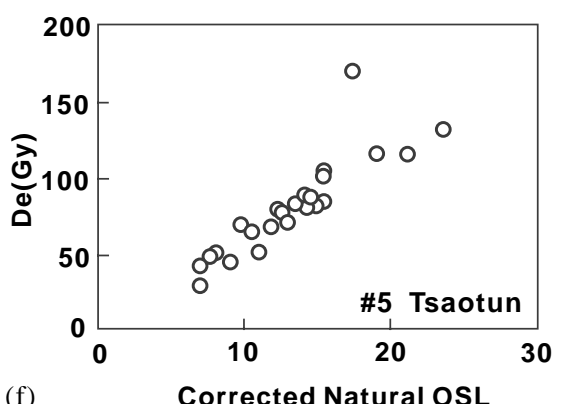

Fig. 3. Dose recovery test $(a, b)$ and growth curve $(c, d)$ for OSL samples collected from river terrace at Hsinshe and Tsaotun. The growth curve of sample \#2 shows quick saturation, but the natural OSL is still less than the saturation value. The slight decrease of OSL intensity must be caused by unstable luminescence after saturation or related uncertainty. (e) and (f) are plots of natural OSL and 110 degree TL (In/TL; Li, 2001) to identify the true $D_{\mathrm{e}}$ of incompletely bleached samples. 


\section{Discussion}

\subsection{Northern segment: Shihkang to Hsinshe}

Samples $\# 1$ and $\# 2$ were collected from sandy layer intercalated within the fluvial gravel beds, covering on the top of strath terraces. In fact, the terraces are located in the hanging wall which recently underwent uplifting due to the activities of the Chelungpu fault. We assumed

Table 3

The $D_{\mathrm{e}}$ results of OSL dating

\begin{tabular}{|c|c|c|c|c|c|}
\hline \multirow[t]{2}{*}{$\begin{array}{l}\text { Sample } \\
\text { no. }\end{array}$} & \multirow[t]{2}{*}{ Locality } & \multicolumn{2}{|c|}{$\begin{array}{l}\text { All measured } \\
\text { aliquots }\end{array}$} & \multicolumn{2}{|c|}{$\begin{array}{l}\text { Relatively well-bleached } \\
\text { aliquots }\end{array}$} \\
\hline & & $\begin{array}{l}\text { Number } \\
\text { of aliquots }\end{array}$ & $\begin{array}{l}\text { Average } \\
D_{\mathrm{e}}(\mathrm{Gy})\end{array}$ & $\begin{array}{l}\text { Number } \\
\text { of aliquots }\end{array}$ & $\begin{array}{l}\text { Average } \\
D_{\mathrm{e}}(\mathrm{Gy})\end{array}$ \\
\hline$\# 2$ & Hsinshe & 22 & $164.4 \pm 38.5^{\mathrm{a}}$ & 15 & $151.0 \pm 34.6$ \\
\hline \#5 & Tsaotun & 24 & $81.3 \pm 31.8$ & 5 & $43.3 \pm 7.9$ \\
\hline
\end{tabular}

${ }^{\mathrm{a}}$ The error is one standard deviation $(\sigma)$ among the aliquots. the scarp height between the terrace surface and modern plain is the cumulative vertical displacement of the fault. Hence, the long-term vertical slip can be easily derived from the age of the terrace surface. We believe that the thin gravel bed on the strath terrace developed within a short time. Accordingly, the vertical slip rates for Shihkang and Hsinshe can be determined as 8.6-11.7 and $5.6-9.9 \mathrm{~m} / \mathrm{ka}$, respectively, using the maximum and minimum of the ages and scarp heights (i.e., the cumulative vertical offsets; Fig. 4 and Table 4). Although the two records represent different time spans, the results are consistent. Considering the $4-5 \mathrm{~m}$ vertical offset of the 1999 Chi-chi earthquake, the recurrence interval of the northern segment of the Chelungpu fault is about $500-800 \mathrm{yr}$.

\subsection{Central segment: Wufeng to Tsaotun}

Two sites were studied in this segment. Wufeng is a trenching site with one wood sample for ${ }^{14} \mathrm{C}$ in the lower
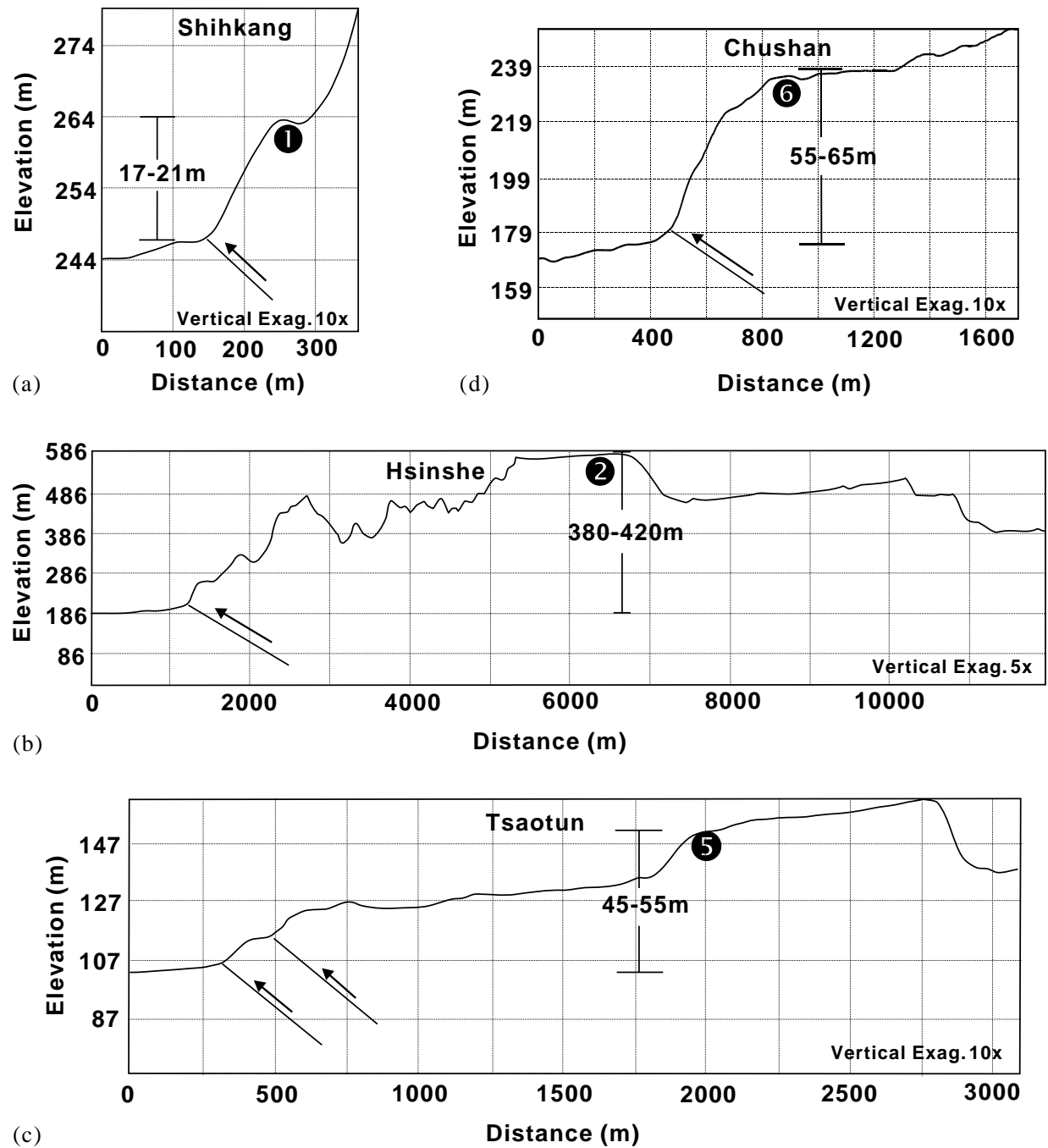

Fig. 4. Topographic profiles of sampling sites: Shihkang (a), Hsinshe (b), Tsaotun (c), and Chushan (d). Also shown are the altitudinal differences between old and modern geomorphic surfaces, which are supposed as the cumulative vertical slips of the recent activities of the Chelungpu fault. 
part of the trench as well as one pottery sample for the TL above. The trench log shows multiple events concentrating on the main thrust plane (Fig. 5; W.S. Chen et al., 2001). The two preliminary ages presented in this paper allow us to compute the vertical slip rate using the ages and vertical displacements in the trench (Fig. 5b), the vertical slip rates are 5.5-6.7 and 4.1$5.0 \mathrm{~m} / \mathrm{ka}$ (Fig. 4 and Table 4). It seems that the rates increased during the past $2000 \mathrm{yr}$. In fact, as we observe from the trenching log that the paleo-soil layer (S1, Fig. 5) has been further bent up in the hanging wall, probably leading to underestimation of the cumulative offset. We believe the slip rate derived from younger deposit is closer to the true value because it underwent less seismic events. In this case, the vertical slip rate approaches $7 \mathrm{~m} / \mathrm{ka}$ (Fig. 4 and Table 4). If the $2-3 \mathrm{~m}$ local vertical offset associated with 1999 earthquake is characteristic, a recurrence interval of 400-700 $\mathrm{yr}$ can be derived.

At Tsaotun there is a strath terrace veneered by fluvial gravel deposits on the top. One OSL sample was collected from a sandy layer intercalated within the gravel bed. The OSL age is supposed to represent the age of the terrace surface. Likewise, the altitudinal difference to the modern streambed (ca. $45-55 \mathrm{~m}$ ) is used as the equivalent vertical displacement caused by faulting. Thus, we can derive a vertical slip rate of $2.8-5.0 \mathrm{~m} / \mathrm{ka}$ for this site (Fig. 4 and Table 4).

Table 4

Vertical slip rates along the Chelungpu fault

\begin{tabular}{llllll}
\hline Sample no. & Locality & Cumulative vertical displacement $(\mathrm{m})$ & Age $(\mathrm{ka})$ & Vertical slip rate $(\mathrm{m} / \mathrm{kyr})$ & Remarks \\
\hline$\# 1$ & Shihkang & $17-21$ & $1.79-1.97(\mathrm{TL})$ & $8.6-11.7$ & This study \\
$\# 2$ & Hsinshe & $380-420$ & $42.4-67.6(\mathrm{OSL})$ & $5.6-9.9$ & This study \\
$\# 3$ & Wufeng & 5.0 & $0.75-0.91(\mathrm{TL})$ & $5.5-6.7$ & This study \\
$\# 4$ & Wufeng & $>7.0$ & $1.4-1.7(\mathrm{C}-14)$ & $>4.1-5.0$ & W.S. Chen et al. (2001) \\
$\# 5$ & Tsaotun & $45-55$ & $11.0-6.0(\mathrm{OSL})$ & $2.8-5.0$ & This study \\
$\# 6$ & Chushan & $55-65$ & $13.2-13.8(\mathrm{C}-14)$ & $4.0-4.9$ & Y.G. Chen et al. (2002b) \\
\hline
\end{tabular}

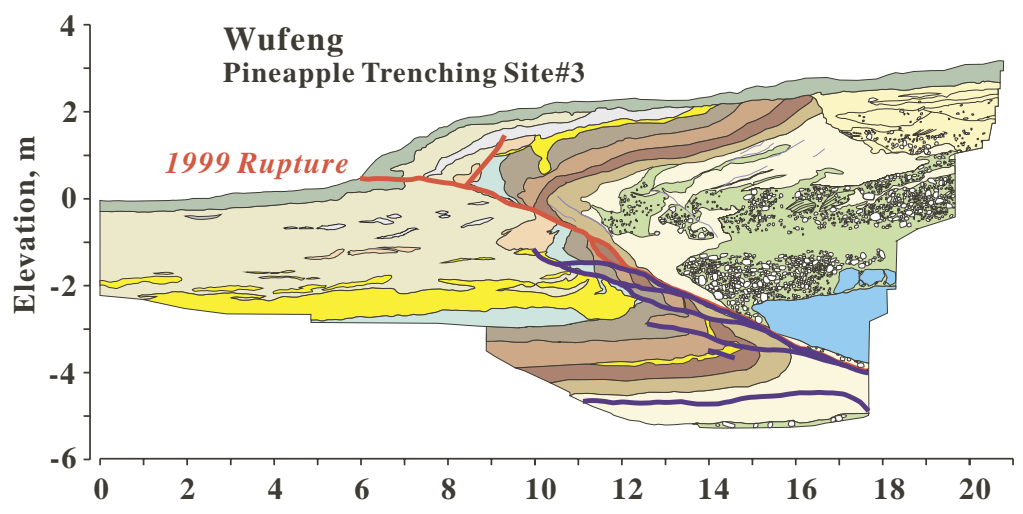

(a)

Distance, $\mathbf{m}$

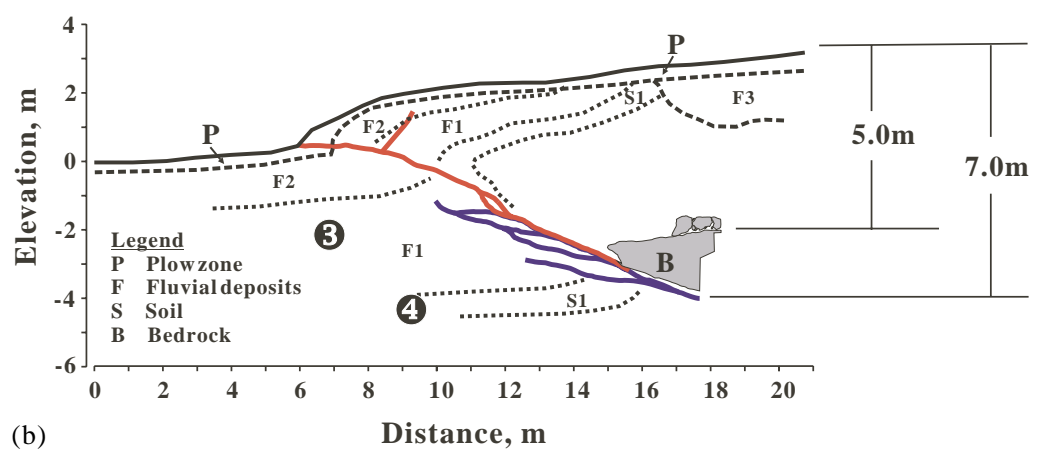

Fig. 5. (a) Sketched log of the Wufeng trenching site. (b) Interpretation of the trenching log and the sampling positions. There are four units identified from paleo-soil (S1) upward including the topmost plow zone. Based on the log the sampling positions have been vertically disrupted at least 5.0 and $7.0 \mathrm{~m}$ respectively. 
Comparing to the 1999 surface deformation, vertically $2.5-3 \mathrm{~m}$, a recurrence interval of roughly $500-1000 \mathrm{yr}$ can be obtained.

\subsection{Southern segment: Chushan}

At Chushan, a river terrace is cut by the Chelungpu fault and the terrace scarp cumulates the offsets of multiple events in the recent past. The terrace scarp shows a profile with $20 \mathrm{~m}$ gravel bed deposited on the bedrock. The gravel bed is identified as debris flow deposits and therein many wood samples were found. Six published radiocarbon samples are spatially scattered and the ages are distributed from 13.2 to $15.1 \mathrm{ka}$ (Y.G. Chen et al., 2002b). This study re-sampled the same site, but collected one sample close to the surface. Therefore, it represents the age of the terrace surface. A vertical slip rate of $4.0-4.9 \mathrm{~m} / \mathrm{kyr}$ can be determined based on the scarp height of 55-65 m (Fig. 4 and Table $3)$. Furthermore, using the 1999 vertical offset of 2.0 $2.5 \mathrm{~m}$ a recurrence interval of $400-600 \mathrm{yr}$ can be estimated.

\subsection{Slip model along the Chelungpu fault}

Based on the slip behavior of an active fault, slip models have been discussed by McCalpin (1996) and Berryman and Beanland (1991). Each model describes a particular slip pattern among the segments along the fault trace, which is essential for seismic hazard assessment. Comparing the long-term slip rates with the coseismic slips, as documented in the 1999 earthquake, they generally show a similar decreasing trend from north to south. This implies that the Chelungpu fault is acting at a relatively constant rate for each segment. Since the detailed paleoseismology studies are not available all along the fault trace, we tentatively derived recurrence intervals for each site by assumption of that the past events were the same as the 1999 event. The result shows the intervals roughly fall into the same range, 400-1000 yr, implying the 1999 earthquake is probably a characteristic event. As a consequence, the slip behavior of the Chelungpu fault is quite similar to the "characteristic slip model" (McCalpin, 1996).

\section{Conclusions}

We successfully applied multiple methods, radiocarbon, TL, and OSL for the determination of the slip rates of an active fault. The six age estimates demonstrate a general decreasing trend of the long-term slip rates from north to south along the Chelongpu fault. This trend is consistent with the observations of the coseismic slip during 1999 Chi-chi earthquake, indicating that the 1999 earthquake is probably a characteristic event. The slip behavior of the Chelungpu fault is very similar to the "characteristic slip model" (McCalpin, 1996).

\section{Acknowledgements}

The project is financially supported by National Science Council, Republic of China under grant numbers of NSC89-2116-M-002-056 and NSC90-2119M-002-009. We are grateful for funding support from Central Geological Survey, Republic of China. We would also like to thank two anonymous reviewers for their valuable and helpful comments and suggestions.

\section{References}

Aitken, M.J., 1985. Thermolumunescence Dating. Academic Press, London, p. 359.

Berryman, K.R., Beanland, S., 1991. Variation in fault behavior in different tectonic provinces of New Zealand. Journal of Structural Geology 13, 177-189.

Bonilla, M.G., 1975. A review of recently active faults in Taiwan. US Geological Survey Open-file Report 75-41, 58 .

CGS, 1999. Investigation report of 921 earthquake geology and map of surface ruptures along the Chelungpu fault during the 1999 Chi-chi earthquake. Central Geological Survey, Ministry of Economic Affairs, Taiwan, ROC (in Chinese)

Chang, H.C., Lin, C.W., Chen, M.M., Lu, S.T., 1998. An introduction to the active faults of Taiwan: explanatory text for the active fault of Taiwan, scale 1:500,000. Spec. Publ. of Cent. Geol. Surv. Taiwan 10, p. 103 (in Chinese with English abstract).

Chen, Y.G., Chen, W.S, Lee, J.C., Lee, Y.H., Lee, C.T., Chang, H.C., Lo, C.H., 2001. Surface rupture of 1999 Chi-chi earthquake yields insights on active tectonics of central Taiwan. Bulletin of the Seismological Society of America 91, 977-985.

Chen, Y.G., Chen, W.S., Wang, Y., Lo, P.W., Lee, J.C., Liu, T.K., 2002a. Geomorphic evidence for prior earthquakes: lessons from the 1999 Chichi earthquake in central Taiwan. Geology 30 (2), 171-174

Chen, Y.G., Shyu, J.B.H., Lai, K.Y., Wang, Y., Chuang, R.Y., Chen, W.S., 2002b. Deformed terraces and active structures: a case along Tungpuna river, Nantao. 2002 Annual Meeting of the Geological Society of China, Abstracts with program, pp. 12-14.

Chen, W.S., Chen, Y.G., Chang, H.C., Lee, Y.H., Lee, K.J., Lee, L.S., Ponti, D.J., Prentice, C., 2001. Paleoseismology of the Chelungpu fault, Central Taiwan. International Symposium on Earthquake and Active Tectonics (iSEAT), Taipei, Taiwan, program proceedings, $101 \mathrm{pp}$.

Ho, C.S., 1988. An introduction to the geology of Taiwan: explanatory text for the geologic map of Taiwan. Minist. Econ. Aff., Taipei, 2nd Edition, 164pp.

Li, S.-H., 1994. Optical dating: insufficiently bleached sediments. Radiation Measurements 23, 563-567.

Li, S.-H., 2001. Identification of well-bleached grains in the optical dating of quartz. Quaternary Science Reviews 20, 1365-1370.

Lin, C.W., Chang, H.C., Lu, S.T., Shih, T.S., Huang, W.J., 2001. An introduction to the active faults of Taiwan: explanatory text for the active fault of Taiwan, scale 1:500,000, 2nd Edition, Spec. Publ. of Cent. Geol. Surv. Taiwan 13, 122pp. (in Chinese with English abstract). 
Ma, K.F., Lee, C.T., Tsai, Y.B., Shin, T.C., Mori, J., 1999. The ChiChi, Taiwan earthquake: large surface displacements on an inland thrust fault. EOS Transactions 80, 605-611.

McCalpin, J.P., 1996. Application of paleoseismic data to seismic hazard assessment and neotectonic research. In: McCalpin, J.P. (Ed.), Paleoseismology, Academic Press, New York, pp. 439-493 (Chapter 9).

Murray, A.S., Wintle, A.G., 2000. Luminescence dating of quartz using an improved single-aliquot regenerative-dose protocol. Radiation Measurements 32, 57-73.

Murray, A.S., Roberts, 1998. Measurement of the equivalent dose in quartz using a regenerative-dose single-aliquot protocol. Radiation Measurements, 29, 503-515.
Page, B.M., Suppe, J., 1981. The Pliocene Lichi Melange of Taiwan: its plate tectonic and olistrostromal origin. American Journal of Science 281, 193-277.

Rubin, C., Sieh, K., Chen, Y.G., Lee, J.C., Chu, H.T., Yeats, R., Mueller, K., Chan, Y.C., 2001. Post-earthquake response, 1999 Chi-Chi earthquake: evidence for past earthquakes. EOS Transactions 82 (47), 565-567.

Stuiver, M., Reimer, P.L., 1993. Extended ${ }^{14} \mathrm{C}$ database and revised CALIB $3.0{ }^{14} \mathrm{C}$ age calibration program. Radiocarbon 35 (1), 215-230.

Teng, L.S., 1990. Geotectonic evolution of late Cenozoic arc-continent collision in Taiwan. Tectonophysics 183, 57-76. 